\title{
Effects of Mechanically Deboned Chicken Meat (MDCM) and Collagen on the Quality Characteristics of Semi-dried Chicken Jerky
}

\author{
Dong-Heon Song ${ }^{1}$, Ji-Hun Choi ${ }^{1}$, Yun-Sang Choi ${ }^{1,2}$, Hyun-Wook Kim¹, Ko-Eun Hwang ${ }^{1}$, Yong-Jae Kim¹, \\ Youn-Kyung Ham${ }^{1}$, and Cheon-Jei Kim ${ }^{1, *}$ \\ ${ }^{1}$ Department of Food Science and Biotechnology of Animal Resources, Konkuk University, Seoul 143-701, Korea \\ ${ }^{2}$ Research Group of Convergence Technology, Korea Food Research Institute, Seongnam 463-746, Korea
}

\begin{abstract}
This study was conducted to determine the effects of using mechanically deboned chicken meat (MDCM) and collagen on quality characteristics of semi-dried chicken jerky. In experiment I, semi-dried chicken jerky was prepared with the replacement of chicken breast with $\operatorname{MDCM}(0,10,20$, and $30 \%)$. The $\mathrm{pH}$ value of the jerky formulated with only chicken breast was 5.94, while the replacement of chicken breast with MDCM significantly increased the $\mathrm{pH}(p<0.05)$. The protein content and shear force of the jerkies decreased with increasing amounts of MDCM, whereas the fat, ash content and processing yield showed the opposite tendency $(p<0.05)$. Replacement with up to $10 \%$ MDCM had no adverse effects on the sensory characteristics of the semi-dried chicken jerky. In experiment II, four levels of pork collagen $(0,1,2$, and $3 \%)$ were added to the semi-dried chicken jerky formulated with $90 \%$ chicken breast and 10\% MDCM. The addition of collagen increased the moisture content, but decreased the ash content of the jerkies produced $(p<0.05)$. The processing yield of the jerkies increased with increasing added amounts of collagen $(p<0.05)$. It was found that the jerkies formulated with $0-2 \%$ collagen had significantly higher overall acceptance score than those prepared with $3 \%$ collagen $(p<0.05)$. In conclusion, MDCM and collagen could be useful ingredients to reduce the production cost and improve the processing yield of semidried chicken jerky. The optimal levels of MDCM and collagen which could be added without adverse effects on the sensory characteristics were up to $10 \%$ and $2 \%$, respectively.
\end{abstract}

Keywords: collagen, mechanically deboned chicken meat (MDCM), semi-dried chicken jerky

\section{Introduction}

Jerky, which is known as a typical intermediate moisture meat product, has been generally manufactured with curing and drying processes (Song, 1997). These processing reduces the water activity, resulting in extension of shelf life by controlling the growth of microorganisms such as Enterobacteriaceae (Allen et al., 2007), Listeria monocytogenes, Staphylococcus aureus and Pasteuri (Naidoo and Lindsay, 2010). Jerky also has several benefits such as; being light, portable, and rich in nutrients, which has led to a recent increase in consumption due to the expansion of its purpose of use into sports and outdoor products (Choi et al., 2008). Contrary to the traditional manufacturing method which used the whole

\footnotetext{
*Corresponding author: Cheon Jei Kim, Department of Food Science and Biotechnology of Animal Resources, Konkuk University, Seoul 143-701, Korea. Tel: +82-2-450-3684, Fax: +822-444-6695, E-mail: kimcj@konkuk.ac.kr
}

muscle, recently, restructuring method has been widely used to utilize various raw materials, low price parts, (Choi et al., 2008) and to readily add functional materials and non-meat sources (Han, 2011; Ku et al., 2013).

Mechanically deboned chicken meat (MDCM) or mechanically deboned poultry meat (MDPM) is produced from edible tissue on chicken bones by deboning or separation techniques. Generally, MDCM is high in lipid and ash content, and contains free heme groups due to the inclusion of bone marrow and particles, compared to fresh meat (Ockerman and Hansen, 2000). For these reasons, MDCM is vulnerable to oxidation and spoilage, and the addition of MDCM to meat products could have a negative effect on the sensory properties, mainly color, flavor, and texture (Pereira et al., 2011). Nevertheless, the inexpensive cost and nutritional value, to provide the effective use of animal resources, are main reasons why studies about the effects of MDCM on the quality characteristics of meat products are still underway. According to Pereira et al. (2011), the levels of MDPM added affected 
the proximate composition and textural properties (cohesiveness and adhesiveness) of frankfurter-type sausages, and conferred a negative effect on cooking yield and color of the final product. In addition, Perlo et al. (2006) reported that addition of washed MDCM up to $40 \%$ increased the fat content but decreased the protein content of chicken nuggets.

Collagen, which is a major structural protein in connective tissues of bone, tendon, and skin, has been extensively used in the food, cosmetic, and pharmaceutical industries (Wang et al., 2014). In the meat industry, collagen is used for several purposes, due to its functional properties including gelling, water-binding, and film-forming (Gómez-Guillén et al., 2011). Generally, it is well known that addition of collagen improves water holding capacity, resulting in increased cooking yield and formation of firm and flexible texture in the final product (Doerscher et al., 2004; Schilling et al., 2003). In addition, the functional effects of collagen on meat products are affected by the amount added, and the type of application in products (Prabhu et al., 2004). Doerscher et al. (2004) reported that the addition of $10 \%$ pork collagen significantly increased the water holding capacity of purified porcine myofibrillar protein gels. Recently, Pereira et al. (2011) examined the combined effect of MDPM and collagen fiber on the quality characteristics of frankfurtertype sausages, and suggested that the addition of collagen could improve the cooking yield and color problems of the final product which resulted from the addition of MDPM. However, there is little information available in the literature related to the combined effects of MDCM and collagen on jerky products, which are manufactured with a relatively long thermal processing time.

Therefore, the objective of this study was to determine the optimum ratio for the replacement of raw material (chicken breast and MDCM), and to evaluate the effects of collagen levels on quality characteristics of semi-dried chicken jerkies formulated with chicken breast and MDCM.

\section{Materials and Methods}

\section{Formulation of semi-dried chicken jerky}

In experiment I, four formulations (100\% chicken breast, $90 \%$ chicken breast and 10\% MDCM, $80 \%$ chicken breast and 20\% MDCM, and $70 \%$ chicken breast and $30 \% \mathrm{MDCM}$ ) were used to determine the optimal replacement ratio of chicken breast and MDCM. In experiment II, four levels of pork collagen $(0,1,2$, and $3 \%)$ were added into semi-dried chicken jerky formulated with $90 \%$ chicken breast and 10\% MDCM. The composition (w/w) of jerky curing solution in each treatment was equally $10 \%$ ice water, $4 \%$ soy sauce, $1.2 \%$ nitrite pickled salt (NPS), 3.3\% red pepper paste, $2 \%$ sugar, $6 \% \mathrm{~d}$-sorbitol, $0.2 \%$ black pepper, $0.1 \%$ ginger powder, $0.2 \%$ garlic powder, $0.2 \%$ onion powder, $0.1 \%$ mono-sodium L-glutamate (MSG), and $0.5 \%$ red pepper powder, based on total raw meat weight.

\section{Manufacturing processing of semi-dried chicken jerky}

Skinless chicken broiler breast fillets (Pectoralis major only, Arbor acre strain, $5 \mathrm{wk}$ of age, approximately 1.5$2.0 \mathrm{~kg}$ live weight) and MDCM were obtained from commercial processing plants. The $\mathrm{pH}$ value of chicken breast and MDCM were 5.72 and 6.78, respectively. All subcutaneous fat and visible connective tissues were removed from the fresh chicken breast muscle. The chicken breast was ground through a $2 \mathrm{~mm}$ plate. The ground chicken breast and MDCM were tumbled at $-3^{\circ} \mathrm{C}$ for $2 \mathrm{~h}$ (MKR150C, Rühle GmbH., Germany) with the jerky curing solution. In experiment II, the pork collagen powder (CP90, Sias Co. Ltd., Korea) was also added in this processing step. The mixture was stuffed into cellulose casing (diameter of $20 \mathrm{~mm}$ ), and the modified drying condition of semi-dried chicken jerky as described by Choi et al. (2008) was carried out as follows; drying $\left(55^{\circ} \mathrm{C}, 30\right.$ min), smoking $\left(65^{\circ} \mathrm{C}, 30 \mathrm{~min}\right)$, slow drying $\left(65^{\circ} \mathrm{C}, 70\right.$ min), slow drying $\left(75^{\circ} \mathrm{C}, 60 \mathrm{~min}\right)$, and dry cooking $\left(75^{\circ} \mathrm{C}\right.$, $10 \mathrm{~min})$. After cooling with chilled air $\left(5^{\circ} \mathrm{C}, 30 \mathrm{~min}\right)$, the semi-dried chicken jerky was individually vacuum-packaged with $\mathrm{PE} /$ nylon film and stored in a $4^{\circ} \mathrm{C}$ refrigerator during analysis.

\section{pH measurements}

The $\mathrm{pH}$ values of sample were determined with a $\mathrm{pH}$ meter (Model 340, Mettler-Toledo GmbH, Switzerland; calibrated with standard solution using $\mathrm{pH} 4.0$ and $\mathrm{pH}$ 7.0). Each sample was triplicated. The $\mathrm{pH}$ values of samples were measured by blending a $5 \mathrm{~g}$ sample with $50 \mathrm{~mL}$ distilled water for $60 \mathrm{~s}$ in a homogenizer at $8,000 \mathrm{rpm}$ (Ultra-Turrax SK15, Janke \& Kunkel, Germany).

\section{Instrumental color evaluation}

Instrumental color of semi-dried chicken jerky were determined using a colorimeter (Minolta Chroma meter CR-210, Japan; calibrated with a white plate, CIE L*= +97.83 , CIE $a^{*}=-0.43, \mathrm{CIE} \mathrm{b}^{*}=+1.98$ ), equipped with a 
$50 \mathrm{~mm}$ aperture. The setting for the illuminant was $\mathrm{C}$ illuminant source and the observer was standard $2^{\circ}$. One measurement on surface of each sample was taken of replicated three. CIE L* (lightness), CIE a* (redness), and $\mathrm{CIE} \mathrm{b}^{*}$ (yellowness) values were recorded.

\section{Proximate composition}

Proximate composition of semi-dried chicken jerkies was analyzed using AOAC (2000) method. Moisture content (950.46B) was determined by weight loss of a $3 \mathrm{~g}$ sample after $12 \mathrm{~h}$ at $105^{\circ} \mathrm{C}$ in an oven (SW-90D, Sang Woo Scientific Co., Korea). Fat content (960.39) was determined by weight loss of $1 \mathrm{~g}$ sample after extraction for $24 \mathrm{~h}$ with petroleum ether in a Soxhlet extraction apparatues (Soxtec $\AA$ Avanti 2050 Auto System, Foss Tecator AB, Sweden). The protein content (981.10) was determined by the Kjeldahl method using $1.2 \mathrm{~g}$ sample with an automatic Kjeldahl nitrogen analyzer (Kjeltec ${ }^{\circledR}$ 2300 Analyzer Unit, Foss Tecator AB, Sweden). The nitrogen conversion factor used 6.25. Ash was determined according to AOAC method 920.153 (muffle furnace) by weight loss of $2 \mathrm{~g}$ sample after heating at $550^{\circ} \mathrm{C}$ for $5 \mathrm{~h}$.

\section{Processing yields}

Processing yield was determined by calculating the weight differences of semi-dried chicken jerkies before and after drying processing as follows;

Processing yield $(\%)=$ [weight of the chicken jerky after drying $(\mathrm{g}) /$ weight of the chicken jerky before drying $(\mathrm{g})] \times 100$

\section{Shear force measurement}

Shear force values of semi-dried chicken jerkies were determined with a Warner-Bratzler shear attachment on a texture analyzer (TA-XT2i, Stable Micro System Ltd., UK). The sample was cut into $5 \mathrm{~cm}$ lengths at room temperature. Test speeds were set at $2 \mathrm{~mm} / \mathrm{s}$. Data were collected and analyzed from the shear force values to obtain for the maximum force required to shear through each sample (Choi et al., 2008).

\section{Rehydration capacity}

Rehydration capacity of semi-dried chicken jerkies was determined using the method of Yun et al. (1988) and Kim et al. (2008) with suitable modification. Each sample was cut into a size of $10 \times 10 \mathrm{~mm}^{2}$. Cut samples were immersed in $50 \mathrm{~mL}$ distilled water. The changes in weight of soaked sample was measured after 5, 10, 15, 30,
45, 60, and $120 \mathrm{~min}$. Rehydration capacity of semi-dried chicken jerkies was calculated as follows;

Rehydration capacity $(\%)=$ [weight of the chicken jerky after rehydration (g) / weight of the chicken jerky before rehydration $(\mathrm{g})] \times 100$

\section{Sensory evaluation}

Semi dried-chicken jerkies formulated with MDCM and/or collagen were assessed for sensory properties by a 10 member trained panel (ASTM, 1981), this members between the ages 20 and 35 . Each samples cut into $1 \mathrm{~cm}$ lengths, were served to the panelists in random order, and the sensory evaluations were performed by the panelists under fluorescence lighting. Panelists were instructed to cleanse their palates between samples using warm water. The color ( $1=$ extremely undesirable, $9=$ extremely desirable), flavor ( $1=$ extremely undesirable, $9=$ extremely desirable), tenderness ( $1=$ extremely tough, $9=$ extremely tender), juiciness ( $1=$ extremely dry, $9=$ extremely juicy), and overall acceptance $(1=$ extremely undesirable, $9=$ extremely desirable) of the samples were evaluated.

\section{Statistical analysis}

All tests were done at least three times for each experimental condition and mean of measurement values were reported. One-way ANOVA was employed to determine the significance of MDCM levels (in experiment I) or collagen level (in experiment II) as a main effect using the SPSS 18.0 software (SPSS Inc, USA). Duncan's multiple range test $(p<0.05)$ was used to determine differences between treatment means. For sensory evaluation data, the principal component analysis (PCA) was performed on the recorded data to categorize the sensory properties of semi-dried chicken jerkies. SPSS 18.0 software was also used for PCA analysis.

\section{Results and Discussion}

\section{Effect of MDCM on physicochemical and textural properties}

The effects of replacing chicken breast with MDCM at different ratios on the physicochemical and textural properties of semi-dried chicken jerkies are shown in Table 1. The $\mathrm{pH}$ value of the jerky formulated with only chicken breast was 5.94, while the replacement of chicken breast with MDCM significantly increased the $\mathrm{pH}(p<0.05)$. However, there was no significant difference in $\mathrm{pH}$ value among the different MDCM treatments due to the repla- 
Table 1. Effect of replacing ratio of chicken breast with mechanically deboned chicken meat (MDCM) on the physicochemical and textural properties of semi-dried chicken jerkies

\begin{tabular}{|c|c|c|c|c|c|}
\hline \multirow{2}{*}{ Traits } & \multicolumn{4}{|c|}{ Replacing percentages (chicken breast / MDCM) } & \multirow{2}{*}{ SEM $^{1)}$} \\
\hline & $100 / 0$ & $90 / 10$ & $80 / 20$ & $70 / 30$ & \\
\hline $\mathrm{pH}$ value & $5.94^{\mathrm{b}}$ & $6.01^{\mathrm{a}}$ & $6.02^{\mathrm{a}}$ & $6.04^{\mathrm{a}}$ & 0.009 \\
\hline \multicolumn{6}{|l|}{ Color characteristics } \\
\hline CIE L* (lightness) & $42.62^{\mathrm{a}}$ & $40.11^{\mathrm{b}}$ & $39.20^{\mathrm{b}}$ & $39.23^{\mathrm{b}}$ & 0.352 \\
\hline CIE a* (redness) & $18.58^{\mathrm{a}}$ & $14.76^{\mathrm{b}}$ & $16.88^{b}$ & $15.99^{b}$ & 0.322 \\
\hline CIE b* (yellowness) & $29.13^{\mathrm{a}}$ & $26.25^{\mathrm{b}}$ & $26.13^{\mathrm{b}}$ & $25.70^{\mathrm{b}}$ & 0.407 \\
\hline \multicolumn{6}{|l|}{ Proximate composition } \\
\hline Moisture (g/100 g) & 49.01 & 48.03 & 48.00 & 49.91 & 0.303 \\
\hline Protein $(g / 100 \mathrm{~g})$ & $33.27^{\mathrm{a}}$ & $32.03^{\mathrm{b}}$ & $29.17^{\mathrm{c}}$ & $26.56^{\mathrm{d}}$ & 0.988 \\
\hline Fat $(\mathrm{g} / 100 \mathrm{~g})$ & $2.73^{\mathrm{d}}$ & $4.23^{\mathrm{c}}$ & $7.41^{\mathrm{b}}$ & $10.01^{\mathrm{a}}$ & 1.101 \\
\hline Ash (g/100 g) & $4.07^{\mathrm{c}}$ & $4.25^{\mathrm{b}}$ & $4.35^{\mathrm{a}}$ & $4.22^{\mathrm{b}}$ & 0.042 \\
\hline Processing yield (\%) & $54.32^{\mathrm{d}}$ & $55.22^{\mathrm{c}}$ & $57.31^{\mathrm{b}}$ & $59.83^{\mathrm{a}}$ & 0.511 \\
\hline Shear force $(\mathrm{kg})$ & $5.60^{\mathrm{a}}$ & $5.44^{\mathrm{ab}}$ & $5.19^{b c}$ & $4.92^{\mathrm{c}}$ & 0.075 \\
\hline
\end{tabular}

${ }^{1}$ SEM: standard error of the means.

${ }^{\mathrm{a}-\mathrm{d}}$ Means within a row with different letters are significantly different $(p<0.05)$.

cement ratio $(p>0.05)$. According to Ockerman and Hansen (2000), the inclusion of red bone marrow and basic calcium phosphate from bone causes an increase in the $\mathrm{pH}$ value of mechanically separated meat. Similarly, Wimmer et al. (1993) reported that the addition of washed mechanically deboned pork at ratios ranging from $20 \%$ to $50 \%$ increased the $\mathrm{pH}$ value of frankfurters. Pereira et al. (2011) also indicated that the addition of MDPM increased the $\mathrm{pH}$ value of the frankfurters, due to high $\mathrm{pH}$ value of MDPM compared to the pork trimmings.

Our results indicated that the color characteristics of the semi-dried chicken jerkies were affected by the replacement of chicken breast with MDCM. The addition of MDCM at levels exceeding 10\% significantly decreased CIE L* (lightness), CIE a* (redness), and CIE $\mathrm{b}^{*}$ (yellowness) of the jerkies $(p<0.05)$. The color characteristic of MDCM is generally reddish color due to the inclusion of hemoglobin separated from the bone marrow during the manufacturing process (Ockerman and Hansen, 2000). In addition, the increased $\mathrm{pH}$ value of MDCM also contributed to the dark red color, with the changes in the absorption properties of myoglobin (Dawson et al., 1988). According to Pereira et al. (2011), the increase in MDPM resulted in decreased lightness, whereas the redness increased up to $50 \%$ addition. They also suggested that the effect of MDPM on the redness is a quadratic term ( $p<$ 0.05 ). In this study, however, the ratio of replacement with MDCM (10-30\%) had no influence on the color characteristics of the semi-dried chicken jerkies $(p>0.05)$. Basically, the color of cooked meat is affected by the myoglobin and hemoglobin content, the cooking method, the cooking time, and the cooking temperature (García-Seg- ovia et al., 2007). Ahn and Maurer (1988) reported that the denaturation temperature (about $50 \%$ denaturation) of hemoglobin and myoglobin are $68^{\circ} \mathrm{C}$ and $78^{\circ} \mathrm{C}$, respectively, and suggested that the heat stability of hemoglobin is inferior compared to that of myoglobin. Also, the color of meat after thermal processing is responsible for the formation of hemichrome, due to the oxidation of myoglobin with heat denaturation (Brewer, 2004). In this study, the temperature of thermal processing was within $75^{\circ} \mathrm{C}$. Thus, the denaturation of hemoglobin from MDCM could greatly contribute to the formation of lower red color in the semi-dried chicken jerky, rather than myoglobin.

Our results indicated that the replacement of chicken breast with MDCM changed the proximate compositions, excluding the moisture content of the jerky. The protein content of the jerkies decreased with increasing amounts of added MDCM, whereas the fat and ash contents showed the opposite tendency $(p<0.05)$. Similarly, Perlo et al. (2006) noted that the addition of hand washed MDCM resulted in increased fat content but decreased protein content. Mechanically deboned meat has a large quantity of unsaturated fats and ash, mainly calcium $(190-230 \mathrm{mg} /$ $100 \mathrm{~g}$ ) and iron (18.7-24.8 mg/100 g), from the bone (Ockerman and Hansen, 2000). For this reason, the replacement of chicken breast with MDCM could cause the observed increase in fat and ash content, resulting in the relative decrease in the protein content of the jerkies.

The processing yield of semi-dried chicken jerky ranged from 54.32 to $59.83 \%$, while an increase in the replacement ratio improved the processing yield $(p<0.05)$. The processing yield of jerky is largely affected by the evaporation of moisture during thermal processing, so the for- 
mulation of meat products is one of the most important factors affecting the processing yield (Choi et al., 2008). In this study, the processing yield of the semi-dried chicken jerkies increased when the replacement ratio increased. This result is probably associated with the inclusion of fat from MDCM. There is little information about the effect of fat content on the processing yield of jerky, because most jerkies are generally prepared with low fat meat parts such as beef eye of round (M. semitendinosus), pork hind leg (M. biceps femoris, M. semitendinosus, $M$. semimembranosus), and chicken breast ( $M$. pectoralis major) (Choi et al., 2008; Han, 2011). In fermented sausage, another dried meat product, Muguerza et al. (2002) noted that the increase in fat content led to a decrease in the weight loss of the fermented sausages. Similarly, our results suggested that the increase in fat content from the addition of MDCM could increase the processing yield of semi-dried chicken jerky.

The replacement of chicken breast with above $20 \%$ MDCM resulted in significantly lower shear force than the control $(p<0.05)$. According to Yang et al. (2009), the shear force value of jerky is greatly related to its moisture content and characteristics, and/or the composition of muscle fibers. In several meat products, on the other hand, the increase in fat content contributes to the formation of a soft texture (Troutt et al., 1992). Thus, the shear force of semi-dried chicken jerky might be largely affected by the

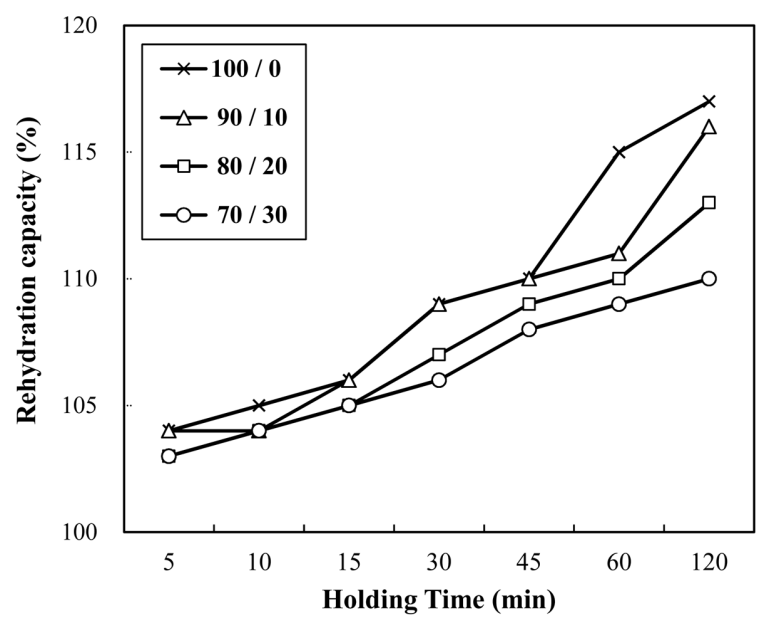

Fig. 1. Effect of replacing ratio of chicken breast with mechanically deboned chicken meat (MDCM) on the rehydration capacity of semi-dried chicken jerkies. $(\times)$, semi-dried chicken jerky formulated with $100 \%$ chicken breast; $(\triangle)$, semi-dried chicken jerky formulated with 90\% chicken breast and 10\% MDCM; ( $\square$ ), semi-dried chicken jerky formulated with $80 \%$ chicken breast and 20\% MDCM; $(\bigcirc)$, semi-dried chicken jerky formulated with $70 \%$ chicken breast and 30\% MDCM. increased fat content from MDCM, as no difference in moisture content among was observed among the treatments.

Rehydration capacity, which is an important factor affecting the sensory properties such as softness and smooth texture in the mouth during mastication, is associated with the hysteresis of dried foods (Rahman, 2008). The effect of replacing chicken breast with MDCM on the rehydration capacity of the semi-dried chicken jerky is shown in Fig. 1. The rehydration capacity for all treatments gradually increased over time. Especially, the control jerky prepared with only chicken breast showed an obvious increment of rehydration capacity after $45 \mathrm{~min}$. The rehydration capacity of the jerky formulated with $90 \%$ chicken breast and 10\% MDCM increased after $60 \mathrm{~min}$. At the final holding time, the rehydration capacity of the jerkies decreased with an increase of the replacement ratio of chicken breast with MDCM. The rehydration capacity is based on the cellular and structural characteristics of dried food (Han, 2011). In this study, the decrease in protein content due to the replacement of chicken breast with MDCM could lead to the formation of poor structure, which led to a decline of the moisture-absorbing ability of the semi-dried chicken jerky.

\section{Effect of MDCM on sensory properties}

The sensory properties of the semi-dried chicken jerkies inferred by the replacement of chicken breast with MDCM are presented in Table 2. With increasing replacement ratio of chicken breast with MDCM, significant decreases in satisfaction of the color, flavor, tenderness, and juiciness were observed $(p<0.05)$. Generally, it is well known that MDCM causes a decline in the sensory characteristics such as color, flavor, and texture, which may mainly be the result of protein denaturation during the mechanical separation, and the inclusion of lipids and free heme groups from the bone (Ockerman and Hassen, 2000; Pereira et al., 2011). To determine the main factors that led to the decline of the sensory properties of the jerky, principal component analysis (PCA) was performed (Fig. 2). The principal components (PC1 and PC2) explained $62.63 \%$ and $20.73 \%$ of the total variation, respectively. In addition, the overall acceptance of the jerkies highly correlated with the tenderness and flavor $(p<0.05)$. In Table 2, the replacement of over $20 \%$ of the chicken breast with MDCM showed a significant decrease in the flavor, tenderness, and juiciness when compared to the control $(p<0.05)$. Thus, the main factors affecting the sensory properties of the semi-dried chicken jerky formulated with chicken breast and MDCM could be flavor and 
Table 2. Effect of replacing ratio of chicken breast with mechanically deboned chicken meat (MDCM) on the sensory properties of semi-dried chicken jerkies

\begin{tabular}{cccccc}
\hline \hline \multirow{2}{*}{ Traits ${ }^{1)}$} & \multicolumn{4}{c}{ Replacing percentages (chicken breast/MDCM) } & \multirow{2}{*}{ SEM $^{2)}$} \\
\cline { 2 - 5 } & $100 / 0$ & $90 / 10$ & $80 / 20$ & $70 / 30$ & 0.105 \\
Color & $8.67^{\mathrm{a}}$ & $8.50^{\mathrm{a}}$ & $8.17^{\mathrm{ab}}$ & $7.67^{\mathrm{b}}$ & 0.064 \\
Flavor & $8.33^{\mathrm{a}}$ & $8.17^{\mathrm{ab}}$ & $8.00^{\mathrm{b}}$ & $8.00^{\mathrm{b}}$ & 0.153 \\
Tenderness & $8.03^{\mathrm{a}}$ & $7.87^{\mathrm{ab}}$ & $7.46^{\mathrm{bc}}$ & $7.25^{\mathrm{c}}$ & $6.42^{\mathrm{c}}$ \\
Juiciness & $8.46^{\mathrm{a}}$ & $8.13^{\mathrm{a}}$ & $7.04^{\mathrm{b}}$ & 7.199 & 0.126 \\
Overall acceptance & $8.67^{\mathrm{a}}$ & $8.33^{\mathrm{a}}$ & $7.67^{\mathrm{b}}$ & $6.92^{\mathrm{c}}$ & 0.126 \\
\hline
\end{tabular}

${ }^{1}$ Traits: color (1=extremely undesirable, $9=$ extremely desirable), flavor ( $1=$ extremely undesirable, $9=$ extremely desirable), tenderness $(1=$ extremely tough, $9=$ extremely tender), juiciness ( $1=$ extremely dry, $9=$ extremely juicy), and overall acceptance ( $1=$ extremely undesirable, $9=$ extremely desirable)

${ }^{2}$ SEM: standard error of the means.

${ }^{\mathrm{a}, \mathrm{b}}$ Means within a row with different letters are significantly different $(p<0.05)$.

tenderness, and the replacement with up to $10 \% \mathrm{MDCM}$ had no adverse effects on the jerky.

\section{Effect of collagen on physicochemical and textural properties}

The effect of collagen levels on the physicochemical and textural properties of semi-dried chicken jerkies formulated with 90\% chicken breast and 10\% MDCM is shown in Table 3. The collagen level had no influence on the $\mathrm{pH}$ value of the jerkies $(p>0.05)$. Similar result was observed by Kenney et al. (1992), who noted that the addition of 5 and $10 \%$ connective tissue, which is rich in collagen, had no impact on the $\mathrm{pH}$ value of restructured beef. In terms of color characteristics, the redness and yellowness of the jerkies slightly decreased with increasing amounts of collagen added, and the jerkies containing up to $3 \%$ collagen showed lower redness and yellowness than those formulated without collagen $(p<0.05)$. How-

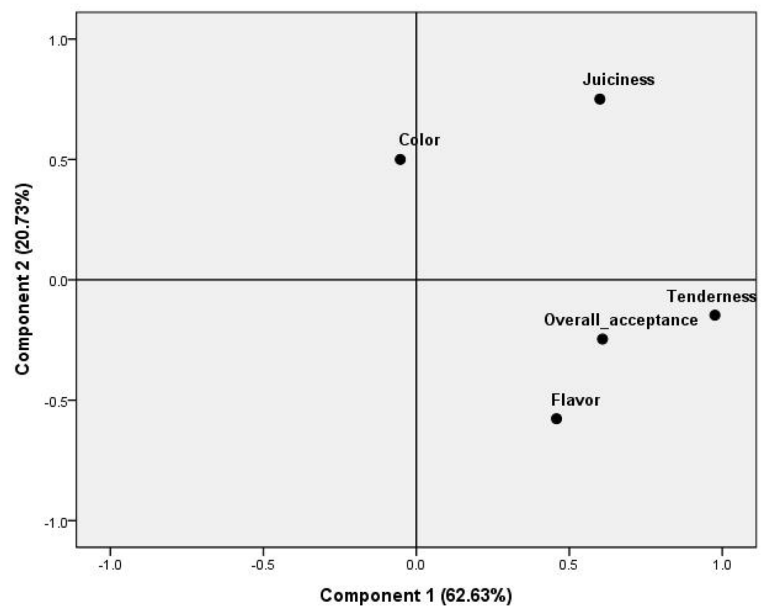

Fig. 2. Principle component analysis (PCA) for plot based on sensory properties of semi-dried chicken jerkies by replacing chicken breast with mechanically deboned chicken meat (MDCM, 0-30\%). ever, no significant difference in lightness was observed among the different treatments $(p>0.05)$. Prabhu et al. (2004) reported that the addition of pork collagen from $0 \%$ to $3.5 \%$ gradually increased the interior yellowness of frankfurters, whereas it did not affect the lightness and redness. Schilling et al. (2003) indicated that the addition of $3 \%$ collagen to boneless cured ham prepared with pale, soft, and exudative pork (PSE) increased the yellowness due to the higher yellowness of collagen compared with the PSE meat. Additionally, Pereira et al. (2011) noted that there was no linear correlation between collagen level and color parameters such as lightness, redness, and chroma values, and suggested that the color characteristics of frankfurters formulated with collagen (0-1\%) fiber and MDPM (0-100\%) were differently affected based on the level of MDPM added. Thus, when collagen is added to meat products, the color characteristics of the final products might differ from the different color properties between the raw materials and collagen. In this study, a mixture of $90 \%$ chicken breast with MDCM showed higher redness and yellowness (data not shown). As a result, the addition of collagen could decrease the redness and yellowness of the jerkies.

The addition of collagen increased the moisture content, but decreased the ash content of the jerkies $(p<0.05)$. However, there were no significant differences in protein and fat content among the treatments $(p>0.05)$. Prabhu et al. (2004) reported a similar result, noting that the addition of pork collagen (up to $3.5 \%$ ) had no influence upon the fat, moisture, and protein contents of frankfurters. Pereira et al. (2011) also reported that the effect of collagen on the composition of frankfurters prepared with collagen and MDPM was reduced by the dilution of collagen in the final product. Our results were partially in agreement with the changes in protein and fat content with the addition of collagen, which was reported by Pereira et 
Table 3. Effect of collagen level on the physicochemical and textural properties of semi-dried chicken jerkies formulated with $\mathbf{9 0 \%}$ chicken breast and $10 \%$ mechanically deboned chicken meat (MDCM)

\begin{tabular}{|c|c|c|c|c|c|}
\hline \multirow{2}{*}{ Traits } & \multicolumn{4}{|c|}{ Added amount of collagen (\%) } & \multirow{2}{*}{$\mathrm{SEM}^{2}$} \\
\hline & 0 & 1 & 2 & 3 & \\
\hline $\mathrm{pH}$ value & 5.88 & 5.87 & 5.92 & 5.90 & 0.003 \\
\hline \multicolumn{6}{|l|}{ Color characteristics } \\
\hline CIE L* (lightness) & 35.99 & 37.47 & 36.35 & 35.57 & 0.204 \\
\hline CIE a* (redness) & $20.19^{\mathrm{a}}$ & $19.65^{\mathrm{ab}}$ & $19.55^{\mathrm{b}}$ & $18.51^{\mathrm{c}}$ & 0.133 \\
\hline CIE b* (yellowness) & $24.13^{\mathrm{ab}}$ & $24.80^{\mathrm{a}}$ & $23.59^{b}$ & $20.66^{\mathrm{c}}$ & 0.328 \\
\hline \multicolumn{6}{|l|}{ Proximate composition } \\
\hline Moisture (g/100 g) & $45.84^{\mathrm{b}}$ & $45.85^{\mathrm{b}}$ & $46.12^{\mathrm{b}}$ & $48.84^{\mathrm{a}}$ & 0.606 \\
\hline Protein $(g / 100 \mathrm{~g})$ & 31.57 & 32.03 & 33.04 & 33.15 & 0.252 \\
\hline Fat $(g / 100 g)$ & 5.14 & 5.04 & 5.04 & 5.15 & 0.210 \\
\hline $\operatorname{Ash}(g / 100 \mathrm{~g})$ & $4.48^{\mathrm{b}}$ & $4.54^{\mathrm{a}}$ & $4.44^{\mathrm{c}}$ & $4.11^{\mathrm{d}}$ & 0.064 \\
\hline Processing yield (\%) & $56.37^{\mathrm{c}}$ & $56.62^{\mathrm{c}}$ & $57.69^{b}$ & $59.02^{\mathrm{a}}$ & 0.266 \\
\hline Shear force $(\mathrm{kg})$ & $6.17^{\mathrm{a}}$ & $6.27^{\mathrm{a}}$ & $6.81^{\mathrm{b}}$ & $7.19^{\mathrm{b}}$ & 0.108 \\
\hline
\end{tabular}

${ }^{1)}$ All values are mean \pm standard deviation.

${ }^{2}$ SEM: standard error of the means.

${ }^{\mathrm{a}-\mathrm{c}}$ Means within a row with different letters are significantly different $(p<0.05)$.

al. (2011).

The processing yield of the semi-dried chicken jerkies formulated with $0-3 \%$ collagen ranged from 56.37 to $59.02 \%$, while it increased with increasing amounts of added collagen $(p<0.05)$. Generally, the insoluble collagen converts into gelatin (soluble) during thermal processing (above $45^{\circ} \mathrm{C}$ ) when collagen is added to meat products. The gelatin produced has the ability to form a gel, which contributes to rheological functionality and thermal stability (Gómez-Guillén et al., 2011). For these reasons, collagen and/or gelatin have extensively been used to improve the cooking yield and textural properties in several meat products, such as boneless ham (Schilling et al., 2003), frankfurters (Pereira et al., 2011), jerky (Kim, 2011), meat balls (Hsu and Sun, 2006), and restructured ham (Prabhu et al., 2004). Kim (2011) reported that semidried chicken jerky prepared with $2 \%$ wheat fiber and $2 \%$ chicken feet gelatin showed a significantly higher drying yield than that without. Meanwhile, the shear force of the semi-dried chicken jerkies decreased with the increasing amount of chicken feet gelatin added. In contrast, the increase in collagen levels in our study resulted in a slight increase of the shear force, despite the increase in moisture content. A similar result was also noted by Pereira et al. (2011) who found a significantly positive linear correlation between collagen fiber levels and the hardness of frankfurters $(p<0.10)$, and suggested that the increased hardness due to the addition of collagen can positively affect the textural properties of the frankfurters formulated with collagen fiber and MDPM, since it somewhat counteracts the decrease in hardness caused by MDPM.
This tendency was observed with increasing collagen levels in frankfurters in another study (Prabhu et al., 2004). Doerscher et al. (2004) indicated that the addition of up to $10 \%$ pork collagen improved the water holding capacity, as well as maintenance of the myofibril gel structure. Thus, our results suggested that the increase in both drying yield and shear force might be related to the gel forming ability and water holding capacity of the collagen added.

The effect of collagen levels on the rehydration capacity of the semi-dried chicken jerkies formulated with $90 \%$

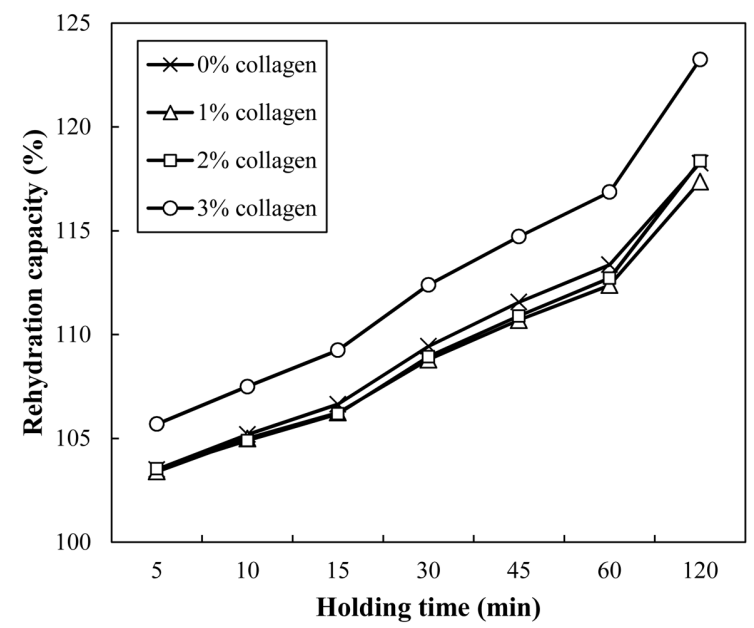

Fig. 3. Effect of collagen level on the rehydration capacity of semi-dried chicken jerkies formulated with $90 \%$ chicken breast and $10 \%$ mechanically deboned chicken meat (MDCM). $(\times)$, semi-dried chicken jerky formulated with $0 \%$ collagen; $(\triangle), 1 \%$ collagen; $(\square), 2 \%$ collagen; $(\bigcirc)$, $3 \%$ collagen. 
Table 4. Effect of collagen level on the sensory properties of semi-dried chicken jerkies formulated with $90 \%$ chicken breast and $10 \%$ mechanically deboned chicken meat (MDCM)

\begin{tabular}{|c|c|c|c|c|c|}
\hline \multirow{2}{*}{ Traits $^{1)}$} & \multicolumn{4}{|c|}{ Added amount of collagen (\%) } & \multirow{2}{*}{$\mathrm{SEM}^{2)}$} \\
\hline & 0 & 1 & 2 & 3 & \\
\hline Color & 9.00 & 8.90 & 8.90 & 8.80 & 0.093 \\
\hline Flavor & 8.90 & 8.90 & 8.80 & 8.50 & 0.097 \\
\hline Tenderness & $8.50^{\mathrm{ab}}$ & $8.70^{\mathrm{a}}$ & $8.40^{\mathrm{ab}}$ & $7.80^{\mathrm{b}}$ & 0.136 \\
\hline Juiciness & $8.40^{\mathrm{a}}$ & $8.40^{\mathrm{a}}$ & $8.20^{\mathrm{a}}$ & $7.30^{\mathrm{b}}$ & 0.135 \\
\hline Overall acceptance & $8.70^{\mathrm{a}}$ & $8.90^{\mathrm{a}}$ & $8.60^{\mathrm{a}}$ & $7.80^{\mathrm{b}}$ & 0.101 \\
\hline
\end{tabular}

${ }^{1}$ Traits: color $(1=$ extremely undesirable, $9=$ extremely desirable), flavor $(1=$ extremely undesirable, $9=$ extremely desirable), tenderness $(1=$ extremely tough, $9=$ extremely tender), juiciness ( $1=$ extremely dry, $9=$ extremely juicy), and overall acceptance ( $1=$ extremely undesirable, $9=$ extremely desirable)

${ }^{2)}$ SEM: standard error of the means.

${ }^{a, b}$ Means within a row with different letters are significantly different $(p<0.05)$.

chicken breast and 10\% MDCM is given in Fig. 3. At all holding times, an obvious increase in the rehydration capacity of the jerky containing 3\% collagen was observed; however, there was no difference among the jerkies prepared with $0-2 \%$ collagen. Kim (2011) reported a similar result, noting that the addition of $1-2 \%$ chicken feet gelatin had no influence on the rehydration capacity of semidried chicken jerkies.

\section{Effect of collagen on sensory properties}

The effect of collagen level on the sensory properties of the semi-dried chicken jerkies formulated with $90 \%$ chicken breast and 10\% MDCM is shown in Table 4. Our results indicated that the addition of collagen above 3\% significantly decreased the satisfaction scores for tenderness and juiciness $(p<0.05)$. However, the color and flavor of the jerkies was not affected by the amount of

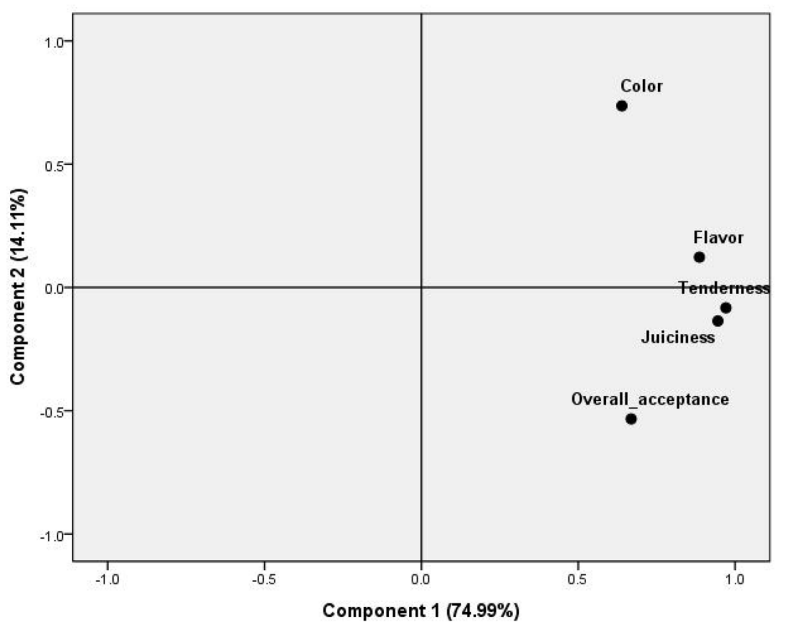

Fig. 4. Principle component analysis (PCA) for plot based on sensory properties of semi-dried chicken jerkies formulated with $90 \%$ chicken breast, $10 \%$ mechanically deboned chicken meat (MDCM), and various levels of collagen $(0-3 \%)$. collagen added $(p>0.05)$. This result may be associated with the increased shear force due to the addition of collagen. The result of PCA is presented in Fig. 4. The juiciness and tenderness were highly correlated with the overall acceptance of the jerkies. Consequently, the jerkies formulated with $0-2 \%$ collagen had a significantly higher overall acceptance score than those prepared with $3 \%$ collagen $(p<0.05)$. In previous studies, although the sensory characteristics differed from the type of final product, addition of collagen more than $2 \%$ resulted in a decided difference in the sensory characteristics of frankfurters when compared to those without collagen. In restructured ham, a significant difference was observed at the $1 \%$ collagen level (Prabhu et al., 2004).

In this study, the increase in replacement ratio of chicken breast with MDCM improved the processing yield of semi-dried chicken jerky, but resulted in the alteration of color, shear force, and sensory characteristics due to the excessive inclusion of fat from MDCM. The optimal replacement level was determined to be $10 \%$, to maintain the quality characteristics of the jerky, along with an economical advantage. Moreover, the addition of collagen increased the product yield and shear force of the semidried chicken jerky formulated with $90 \%$ chicken breast and $10 \%$ MDCM. The addition of collagen up to $2 \%$ had no negative effects on the sensory characteristics of the jerky. In conclusion, MDCM and collagen could be useful ingredients to reduce the production cost and improve the processing yield of semi-dried chicken jerky. The optimal levels of MDCM and collagen to avoid adverse effects on sensory characteristics were up to $10 \%$ and $2 \%$, respectively.

\section{Acknowledgements}

This research was supported (60800-05-3-SB310) by 
the Ministry of agriculture, Food and Rural Affairs (Republic of Korea). The authors were supported by the Brain Korean 21 Plus (BK 21 Plus) Project from Ministry of Education and Human Resources Development.

\section{References}

1. Ahn, D. U. and Maurer, A. J. (1989) Effects of sodium chloride, phosphate, and dextrose on the heat stability of purified myoglobin, hemoglobin, and cytochrome c. Poultry Sci. 68, 1218-1225.

2. Allen, K., Cornforth, D., Whittier, D., Vasavada, M., and Nummer, B. (2007) Evaluation of high humidity and wet marinade methods for pasteurization of jerky. J. Food Sci. 72, C351-C355.

3. AOAC (2000) Official methods of analysis. 17th ed, Association of Official Analytical Chemists, Washington, DC, USA.

4. ASTM (1981) American Society for Testing and Materials. Guidelines for the selection and training of sensor and panel members. ASTM STP 758, ASTM Philadelphia, 3-33.

5. Brewer, S. (2004) Irradiation effects on meat color-A review. Meat Sci. 68, 1-17.

6. Choi, J. H., Jeong, J. Y., Han, D. J., Choi, Y. S., Kim, H. Y., Lee, M. A., Lee, E. S. Paik, H. D., and Kim, C. J. (2008) Effects of pork/beef levels and various casings on quality properties of semi-dried jerky. Meat Sci. 80, 278-286.

7. Dawson, P. L., Sheldon, B. W., and Ball, H. R. Jr. (1988) Extraction of lipid and pigment components from mechanically deboned chicken meat. J. Food Sci. 53, 1615-1617.

8. Doerscher, D. R., Briggs, J. L., and Lonergan, S. M. (2004) Effects of pork collagen on thermal and viscoelastic properties of purified porcine myofibrillar protein gels. Meat Sci. 66, 181-188

9. García-Segovia, P., Andrés-Bello, A., and Martínez-Monzó, J. (2007) Effect of cooking method on mechanical properties, color and structure of beef muscle (M. pectoralis). J. Food Eng. 80, 813-821.

10. Gómez-Guillén, M. C., Giménez, B., López-Caballero, M. E., and Montero, M. P. (2011) Functional and bioactive properties of collagen and gelatin from alternative sources: A review. Food Hydrocolloid. 25, 1813-1827.

11. Han, D. J. (2011) Effects of hot-boning, tumbling, meat composition, and non-meat ingredients on the quality properties of jerky. Ph.D. thesis, Konkuk Univ., Seoul, Korea.

12. Hsu, S. Y. and Sun, L. Y. (2006) Comparisons on 10 nonmeat protein fat substitutes for low-fat Kung-wans. J. Food Eng. 74, 47-53.

13. Kenney, P. B., Kastner, C. L., and Kropf, D. H. (1992) Raw and preheated epimysium and gelatin affect properties of low-salt, low-fat, restructured beef. J. Food Sci. 57, 551-554.

14. Kim, H. Y. (2011) Utilization of wheat fiber, chicken skin and feet hydrolyzates as a binder of extender in chicken meat products. Ph.D. thesis, Konkuk Univ., Seoul, Korea.

15. Kim, J. M., Choi, J. H., Han, D. J., Choi, Y. S., Jeong, J. Y., Choi, G. H., Paik, H. D., and Kim, C. J. (2008) Effect of protease produced from Bacillus polyfermenticus SCD on quality of jerky. Food Sci. Biotechnol. 17, 389-395.
16. Ku, S. K., Park, J. D., Lee, N. H., Kim, H. J., and Kim, Y. B. (2013) Physicochemical and sensory properties of restructured jerky with four additives. Korean J. Food Sci. An. 33, 572-580.

17. Muguerza, E., Fista, G., Ansorena, D., Astiasaran, I., and Bloukas, J. G. (2002) Effect of fat level and partial replacement of pork backfat with olive oil on processing and quality characteristics of fermented sausages. Meat Sci. 61, 397-404.

18. Naidoo, K. and Lindsay, D. (2010) Survival of Listeria monocytogenes, and enterotoxin-producing Staphylococcus aureus and Staphylococcus pasteuri, during two types of biltongmanufacturing processes. Food Control 21, 1042-1050.

19. Ockerman, H. W. and Hansen, C. L. (2000) Edible tissue from bone: Animal by-product processing \& utilization. 1st ed, CRC Press, Boca Raton, pp. 217-246.

20. Pereira, A. G., Ramos, E. M., Teixeira, J. T., Cardoso, G. P., Ramos, A. L. S. R., and Fontes, P. R. (2011) Effects of the addition of mechanically deboned poultry meat and collagen fibers on quality characteristics of frankfurter-type sausages. Meat Sci. 89, 519-525.

21. Perlo, F., Bonato, P., Teira, G., Fabre, R., and Kueider, S. (2006) Physicochemical and sensory properties of chicken nuggets with washed mechanically deboned chicken meat. Meat Sci. 72, 785-788.

22. Prabhu, G. A., Doerscher, D. R., and Hull, D. H. (2004) Utilization of pork collagen protein in emulsified and whole muscle meat products. J. Food Sci. 69, C388-C392.

23. Rahman, M. S. (2008) Post-drying aspects for meat and horticultural products. In: Drying technologies in food processing. Chen, X. D. and Mujumdar, A. S. (eds) Blackwell Publishing, Oxford, pp. 252-269.

24. Schilling, M. W., Mink, L. E., Gochenour, P. S., Marriott, N. G., and Alvarado, C. Z. (2003) Utilization of pork collagen for functionality improvement of boneless cured ham manufactured from pale, soft, and exudative pork. Meat Sci. 65, 547553.

25. Song, H. H. (1997) (The) Effects of glycerol, rice syrup and honey on the quality and storage characteristics of beef jerky. Master. Thesis, Konkuk Univ., Seoul, Korea.

26. Troutt, E. S., Hunt, M. C., Johnson, D. E., Claus, J. R., Kastner, C. L., Kropf, D. H., and Stroda, S. (1992) Chemical, physical, and sensory characterization of ground beef containing 5 to 30 percent fat. J. Food Sci. 57, 25-29.

27. Wang, L., Liang, Q., Chen, T., Wang, Z., Xu, J., and Ma, H. (2014) Characterization of collagen from the skin of Amur sturgeon (Acipenser schrenckii). Food Hydrocolloid. 38, 104109.

28. Wimmer, M. P., Sebranek, J., and McKeith, F. (1993) Washed mechanically separated pork as a surimi-like meat product ingredient. J. Food Sci. 58, 254-258.

29. Yang, H. S., Hwang, Y. H., Joo, S. T., and Park, G. B. (2009) The physicochemical and microbiological characteristics of pork jerky in comparison to beef jerky. Meat Sci. 82, 289-294.

30. Yun, Y. J., Kim, K., Kim, S. K., Park, D. Y., and Park, Y. K. (1988) Hydration rates and changes of hardness during soaking of polished naked barleys. J. Korean Agric. Chem. Soc. 31, 21-25.

(Received 2014.6.23/Revised 2014.8.6/Accepted 2014.8.8) 